\title{
Cerebus, un modelo de edición independiente
}

\section{Cancio, José Luis [ver currículum del autor, docente de la Facultad de Diseño y Comunicación]}

Resumen: Se trata de un ensayo sobre una de las mayores obras de la historieta internacional, un hito en el cómic independiente realizado fuera del mainstream industrial y quizá una de las series que más han influido formalmente en el medio: Cerebus.

Palabras clave: comic - historieta Cerebus - Canadá.

$\left(^{*}\right)$ Realizador audiovisual (CIEVYC). Se desempeña como docente en diversas instituciones. Integra el jurado de distintas convocatorias cinematográficas. Es docente de la Facultad de Diseño y Comunicación desde el año 2012.

Introducción

El siguiente texto tiene como finalidad analizar Cerebus, The Aardwark, la historieta creada por Dave Sim, focalizando el estudio en dos aspectos: por un lado, las diversas influencias artísticas en la obra; y por otro, el impacto de su publicación en el mercado editorial independiente de historietas.

I. De cómo se relacionan en el inicio un cerdo hormiguero, Kafka y una sobredosis de LSD

En una entrevista1 realizada a Dave Sim en 2004 se le pregunto acerca del por qué había elegido a un cerdo hormiguero como protagonista de Cerebus. Sim respondió que la formulación de semejante interrogante le parecía absurda; según él, era como si a Kafka le hubieran preguntado por qué había elegido a una cucaracha como personaje de La metamorfosis.

Cerebus comenzó como una publicación bimestral en 1977. La intención de Sim era crear una parodia de la versión de Conan dibujada por Barry Windsor-Smith para la editorial Marvel Comics, con una clara influencia en sus guiones de Howard The Duck de Steve Gerber. De Barry Windsor-Smith tomó prestado la expansión dramática en la viñeta y la elegancia del trazo en blanco y negro. De Gerber, el humor incómodo y la idea de no 
encasillar la historia en un solo género dramático, dotando al argumento de distintos niveles de emoción y comprensión. Esta primera etapa se caracteriza por una consolidación en el relato secuencial. En los primeros 11 números de Cerebus podemos ver a un Dave Sim de 21 años progresando en la calidad de sus dibujos, homenajeando en ciertas composiciones de página tanto a Neal Adams como a Will Eisner. En el guión, todo sirve de excusa para experimentar con el relato; fragmenta sueños, divide secuencias temporales en distintos momentos y utiliza múltiples puntos de vista. Todo continúa en esa dirección hasta 1979, cuando Sim es internado en un hospital después de una sobredosis de LSD. Durante su internación sufre alucinaciones y se le diagnostica esquizofrenia. Es en este periodo en donde Sim decide desarrollar la historia de Cerebus en un arco argumental de 300 números, imaginando el fin de la trama con la muerte del personaje en su vejez, solo y abandonado. En numerosas ocasiones Sim se refiere a ese momento de su vida como si se hubiera tenido una visión de El Aleph, el artilugio imaginado por Jorge Luis Borges. Más allá del carácter mítico que le infiere el autor, lo verdadero es que aquella internación es un punto de inflexión en el desarrollo de la historieta independiente. A partir de 1979, Cerebus deja de ser una mera parodia, para transformarse en otra cosa: la edición de Cerebus abandona el formato fanzine, pasa a ser mensual, y Dave Sim empieza a imaginar la construcción de una de las historietas más extensas y complejas del habla anglosajona, diseñando la saga de Cerebus a lo largo de 6.000 páginas y 15 arcos argumentales.

II. De la manera en que la política de un Maquiavelo similar a Groucho Marx se ve revelada en una cucaracha

En 1981, a partir del número 26 de la serie, Dave Sim comienza la primera saga argumental de la obra, Alta Sociedad. Allí, Cerebus se convierte en una pieza más del engranaje de una historia crítica. Lentamente, la progresión del guión se aleja de la mera ironía, tomando como eje central la idea misma de la política y el poder. Para ello, transforma a Lord Julius, uno de los personajes más cínicos de la historia, en la viva personificación de Groucho Marx. Los diálogos que Sim pone en boca de Julius giran en comentarios absurdos y estilizados respecto a la elección de Cerebus como primer ministro de la ciudad-estado de lest. Julius lo manipulará como una marioneta en beneficio de diferentes intereses y conglomerados económicos. En esta saga también se desarrolla otro personaje secundario que empieza a tomar más protagonismo: Artemio, la Cucaracha Luna, que no es más que una representación crítica de los pensamientos de Dave Sim respecto a la industria de los superhéroes en las historietas. La cucaracha Luna es un superhéroe desquiciado, casi patético, que de acuerdo al tono de cada saga, adquiere la personalidad de algún superhéroe clásico: puede transformarse en Wolverine, Moon night, Capitán America o Sandman. De esta manera, Sim también rinde homenaje a aquellos artistas que influenciaron su obra, como Neal Adams, Frank Miller, Bill Sienkiewicz. En este punto, la parodia, el humor y los homenajes a grandes autores de historieta se empiezan a fusionar en un tono específico. En la primera saga argumental de Cerebus, Sim logra consolidar un estilo propio.

...Y el humor es parte de la vida. También lo es la aventura, también lo es "algo de horror", la política, los temas sociales y existenciales. Cada vida tiene abundancia de todas esas cosas, de manera que no entiendo por qué la mayoría de trabajos creativos eligen una categoría y se ciñen a ella... ALTA SOCIEDAD es un cómic de humor. También es una novela política. También es una parodia política. También es una novela de fantasía. También es una parodia de los superhéroes. También es un cómic funny animals. La gente no estaba acostumbrada a esto hace treinta años, y ahora están menos acostumbrados...

III. De los paisajes del nuevo mundo cuando el sol del oriente se vislumbra en el horizonte y de la manera en que la conciencia viaja a Plutón 
A partir de las dos siguientes sagas argumentales, Iglesia y Estado I y II, los cambios realizados con anterioridad se asientan. El dibujo de Sim se desarrolla con más libertad al sumar al dibujante Gerard en la realización de los fondos de Cerebus. La estilización híper realista es la principal cualidad del dibujo de Gerard. Esta estilización eleva la obra de Dave Sim a otro nivel.

Se podría decir que es en este momento en donde el dibujo y la narración gráfica se consolidan, logrando un estilo que Scott McCloud denomina efecto máscara (McCloud, 1995), es decir, la combinación gráfica de unos personajes grotescos en un entorno realista, como también sucede en el Manga3. Otra característica que acerca la obra de Sim al arte secuencial japonés es una mayor variedad de las transiciones entre viñetas (si se la compara con la mayoría de las historietas occidentales) con una presencia más sustancial de recreaciones de ambientes en donde se crean grandes elipsis de tiempo4. También, en ciertas secuencias de acción en arcos argumentales posteriores, Sim extiende el tiempo del relato progresivo al estilo del Manga más puro, llegando a prescindir inclusive del texto y del diálogo durante varias páginas, como en una secuencia del arco argumental de Reads, cuando Cerebus se lanza en una brutal pelea contra Cirin, la representante de los Cirinistas; un movimiento matriarcal y fascista que impone una dictadura en el reinado de Estarcion. Al respecto de esta relación la opinión de Sim sobre el Manga es interesante y peculiar:

(...) Los manga no son cómics y los cómics no son manga. El manga es manga y los cómics son cómics. Alguien me preguntó porqué CEREBUS no se publica en Japón. Bueno, es porque no es manga, es un cómic. (...) En parte por su andrógina. A menos que los chicos, las chicas, los hombres y las mujeres parezcan iguales salvo pequeñas diferencias, no va a parecer un manga. Parecerá un cómic. Si los hombres parecen de una forma y las mujeres de otra, entonces será más un cómic y no un manga. Son culturas y "maneras de ver las cosas" completamente distintas, creo5.

Pero limitar las influencias de Cerebus solo como manga es, quizás, un error. Los experimentos de Dave Sim con la narración son amplios y excede este escrito. En Alta Sociedad y en Iglesia y Estado I y II, por ejemplo, las páginas pasan de tener una orientación vertical para girar y tornarse apaisadas. Las secuencias se dividen en una gran cantidad de viñetas o en varias splash pages, de forma que la transición de vertical a apaisado se hace en una serie de recuadros dentro de la página, mientras que en otros momentos es la página completa la que gira paulatinamente.

También es importante señalar que el estilo de narración de Cerebus varía según cada saga, otorgándole a la obra un cuerpo estético que resulta improbable de separar de la trama. En el arco argumental de La historia de Jaka, Sim narra la historia de la infancia y juventud de Jaka Tavers, el gran amor de Cerebus. Esta historia idílica y romántica, que se encuentra dentro de otra historia, no se relata con los medios tradicionales de la viñeta y la secuencia, sino con la forma de la novela ilustrada del siglo XIX, acumulando páginas completas o dobles páginas, donde una o dos columnas de texto acompañan a las ilustraciones que se caracterizan por un detallismo y un preciosismo extraordinario, gracias a los fondos realizados por Gerard.

En la saga de Mentes, Sim inventa una historia en donde Cerebus viaja al planeta Plutón volando a través del sistema solar mientras conversa con una voz que aparece en su interior. Al principio Cerebus piensa que se ha vuelto loco o que se ha encontrado con Dios, pero todo se aclarara cuando la voz se presenta como Dave, su creador. Este le comunica a Cerebus que es un personaje de una historia que ha cobrado vida propia a través de sus acciones y que si no cambia su actitud egoísta, lo único que obtendrá será la muerte y la soledad. De 
esta forma -mediante unas espectaculares viñetas del personaje atravesando el sistema solar, un agujero negro y un desolado Plutón- Dave Sim se incorpora a su propia trama como un personaje más, atreviéndose a instaurar una discusión sobre la autoconciencia Hegeliana7 pocas veces vista en la industria de las historietas.

También podemos encontrar un perfeccionamiento en la escritura de los diálogos y de las descripciones. Sim denota un elevado conocimiento del lenguaje, tomando prestado de la literatura lo necesario para perfeccionar su prosa. No sólo es capaz de reproducir casi todos los acentos del idioma Inglés -seguramente esto debe ser una complicación para la edición en español de Cerebus que se está llevando a cabo en España- sino que es capaz de reproducir a la perfección los estilos literarios de Oscar Wilde en la saga de Melmoth, de Scott Fitzgerald en Going Home, o de Ernest Hemingway en Form and Void, llegando a incorporar a los mismos escritores dentro de las sagas.

La poesía también se hace presente, observando una especial influencia del hermetismo italiano de comienzos del siglo XX. Los herméticos defendían una literatura como modelo de vida absoluta, como una revelación integral del ser humano. Buscaron hacer de la palabra un momento puro y absoluto en donde culminaran las tensiones existenciales, manifestando interés en los valores religiosos y místicos. Un ejemplo: a lo largo de los 300 números de Cerebus una extraña frase es repetida por diferentes personajes, incluso por el propio protagonista, como si fuera algo accidental: "Something Fell” (Algo se ha caído). Esta frase, en principio eventual, termina revelándonos un significado casi esotérico en el número 300, al final de la obra, en el momento de la muerte del personaje.

IV. De lo ocurrido y sucedido a un cerdo hormiguero en la lucha contra el matriarcado y de cómo la fe no mueve solamente montañas

Mientras prepara la saga de Mothers and Daughters, la trama de Cerebus cambia y la escritura de Sim se transforma. En el número 186 el autor de Cerebus comienza un largo texto literario de ficción, con resonancias de ensayo, en donde expresa sus ideas sobre la femineidad y la masculinidad, de manera independiente a la lectura de Cerebus. Distribuido en varias secciones de la historieta, Viktor Davis, quizás un alter ego de Dave Sim, expone una teoría sobre la naturaleza de los géneros. Describe a la femineidad como "un vacío femenino" centrado en la emoción, y a la masculinidad como "una luz masculina" centrada en la razón, afirmando que el feminismo es un obstáculo en la búsqueda del conocimiento del ser humano. Las diferentes disquisiciones sobre las mujeres y los hombres que giran alrededor de este texto, lograron enfurecer a cierta parte del público, que malinterpretó la obra de Dave Sim hasta la actualidad. Más controversia suscitó la manera en que manifestó su conversión religiosa (a mediados de los noventa, Dave Sim se declaró creyente ultraortodoxo Judeo, cristiano y musulmán, practicando el celibato y el ascetismo) en una de las últimas sagas de la serie, Latter Days. Allí, en una sección denominada "Persiguiendo a YHWH8 ", el mismo Cerebus proporciona un análisis profundamente taxativo de la Torá. Es inevitable que cuando un autor constituye una obra que se edifica a lo largo de varios años, esa obra se transforme ideológica y artísticamente durante ese período. Los puntos de vistas políticamente incorrectos son discutibles en relación a su entorno social y a su época. Atentar contra Cerebus por la ideología o la religión de su autor, sería tan absurdo como no leer a Jack London porque pensaba que los afro americanos eran seres inferiores o como no recomendar la lectura de los cuentos de Borges porque era anti peronista. 
Si la conciencia es la propiedad del espíritu de reconocerse en sus atributos esenciales y la autoconciencia es un saber que se sabe historia (Ángel Faretta. 2006), podríamos indicar que el autor de Cerebus ha logrado incorporar diversas ideas filosóficas y literarias de una manera armónica y con cierto sentido del humor, sin olvidarse, quizás, que en definitiva, Cerebus es una historia protagonizada por un cerdo hormiguero.

V. Algunas conclusiones de la influencia de un mamífero placentario en el futuro de la manufactura independiente de Historietas

A partir de Alta Sociedad la empresa DC Comics empieza a negociar con Aardvark-Vanaheim la editorial de Dave Sim, por la publicación de Cerebus. En ese momento, la publicación mensual de Cerebus ha alcanzado un importante prestigio, llegando a vender 36.000 ejemplares por número, una cifra substancial para una historieta independiente, pero aún sigue siendo un número que podría aumentar si su distribución llevara el sello de una editorial importante en la portada.

Las negociaciones con DC Comics se prolongan durante años, ya que Dave Sim, un constante defensor de los derechos de autor, pretende un trato justo para ambas partes, por lo que realiza varias propuestas en donde la mayoría de las ganancias son para los autores: él mismo y Gerard. Aunque a mediados de los ochentas DC Comics estaba haciendo avances importantes en este tema, aún no estaba preparada para propuestas económicas radicalmente independientes, con una obra que solo les iba a aportar reputación. De todos modos le hacen a Sim una oferta bastante importante: U\$D 100.000, el 10\% de todo el merchandising generado y la libertad de que se siga publicando de manera independiente nuevos números de Cerebus. En medio de las negociaciones Sim publica la segunda parte de Alta Sociedad en un tomo recopilatorio, muy parecido a los actuales Trade Paperbacks, y lo empieza a distribuir directamente por correo, omitiendo a los distribuidores tradicionales. El resultado es un éxito de ventas: 6.000 ejemplares vendidos hacen ingresar a su editorial U\$D 150.000 . Es en ese momento cuando el autor de Cerebus toma verdadera conciencia de lo risible que resulta la oferta de DC Comics y de que la publicación independiente puede convertirse en un negocio muy lucrativo, a lo que puede dedicarse toda su vida. Este hecho fue uno de los puntos de inflexión más importantes en el mercado independiente norteamericano, ya que por un lado, le facilitó a la editorial de Dave Sim profundizar aún más su postura en defensa de los derechos de autor, y por otro le dio una estabilidad económica que le permitió rechazar la oferta de DC Comics, sirviendo como ejemplo a otras editoriales independientes que surgirían en Estados Unidos en el futuro. Una editorial como Image probablemente no podría haberse conformado si antes Cerebus no hubiera tenido el éxito que tuvo.

A partir de este impulso económico, y de ciertos obstáculos que las distribuidoras gráficas tradicionales empezaban a interponer a su editorial, en 1988 Dave Sim decide convocar a otros dibujantes y autores, como Kevin Eastman, Peter Laird, Scott McCloud, Eric Talbot, Mark Martin, Michael Zulli, Rick Veitch y otros, para escribir una declaración de derechos de autor en donde se proponían muchísimas ideas que hoy en día pueden sonar como elementales, pero que en su momento fueron precursoras. Allí se sostenía que el derecho de autor pertenece a los que creaban la obra; se defendía el derecho a poder editar una publicación donde y como sus autores quisieran; y se bregaba por el control creativo absoluto de todo el material.

Aunque esta declaración no logró que las distribuidoras dejaran de obstaculizar la comercialización de publicaciones independientes, sirvió para que las editoriales como DC Comics o Marvel Comics revisaran sus contratos con los autores. Pero no sólo eso: con el tiempo aquella proclama fue erigiéndose como una especie 
de ideario de donde emergieron las nuevas generaciones de dibujantes y autores de historietas que pronto se lanzarían al mercado con nuevos proyectos de editoriales independientes.

Notas

1. Tasha Robinson, Marzo 31, 2004 - http://www.avclub.com/articles/dave-sim,13861/

2. Entrevista a Dave Sim por Alberto García Marcos. Entrecomics.

3. Cómo se hace un cómic: El arte invisible, Pág. 51-52 y 63, de Scott McCloud. Ediciones B. Barcelona, 1995.

4. Cómo se hace un cómic: El arte invisible, Pág. 86 a 92, de Scott McCloud. Ediciones B. Barcelona, 1995.

5. Entrevista a Dave Sim por Alberto García Marcos. Entrecomics.

6. Según Hegel la autoconciencia ha encontrado la cosa como sí misma y se ha encontrado a sí misma como cosa; es decir, para la autoconciencia la cosa es en sí la realidad objetiva.

7. Según Hegel la autoconciencia ha encontrado la cosa como sí misma y se ha encontrado a sí misma como cosa; es decir, para la autoconciencia la cosa es en sí la realidad objetiva.

8. Un juego de palabras entre "Yahvé" (en hebreo הוהי, YHWH) y la película de Kevin Smith "Persiguiendo a Amy".

Bibliografía

Hegell, G. W. F. (2002). Fenomenología del espíritu. Buenos Aires: Fondo de cultura económica.

McCloud, S. (1995). El Arte Invisible, B, Barcelona.

Abstract: The article presents an essay on Cerebus, one of the most relevant works of international comics.

Cerebus is a milestone in the independent comic that was developed out of the industrial mainstream and that became perhaps one of the most influential series in the comics industry.

Key words: comic - Cerebus - Canadá.

Resumo: O ensaio trata sobre uma das maiores obras da historieta internacional, uma marca no comic independente feito fora do mainstream industrial e uma das séries que mais influiu formalmente no médio: Cerebrus.

Palavras chave: comic - historieta - Cerebus - Canadá.

Cerebus, un modelo de edición independiente fue publicado de la página 63 a página69 en Cuadernos del Centro de Estudios de Diseño y Comunicación № 66 